\title{
On multivariate control charts
}

\author{
Marianne Frisén* \\ *marianne.frisen@statistics.gu.se, University of Gothenburg, Swenden
}

\begin{abstract}
Industrial production requires multivariate control charts to enable monitoring of several components. Recently there has been an increased interest also in other areas such as detection of bioterrorism, spatial surveillance and transaction strategies in finance. In the literature, several types of multivariate counterparts to the univariate Shewhart, EWMA and CUSUM methods have been proposed. We review general approaches to multivariate control chart. Suggestions are made on the special challenges of evaluating multivariate surveillance methods.
\end{abstract}

Keywords

Surveillance. Monitoring. Quality control. Multivariate evaluation. Sufficiency.

\section{Introduction}

Multivariate surveillance is of interest in industrial production, for example in order to monitor several sources of variation in assembled products. Wärmefjord (2004) described the multivariate problem for the assembly process of the Saab automobile. Sahni, Aastveit and Naes (2005) suggest that the raw material and different process variables in food industry should be analysed in order to assure the quality of the final product. Tsung, Li and Jin (2008) described the need for multivariate control charts at manufacturing and service processes. The first versions of modern control charts (SHEWHART, 1931) were made for industrial use. Surveillance of several parameters (such as the mean and the variance) of a distribution is multivariate surveillance (see for example Knoth and Schmid (2002)). Capability index is dealing with both the mean and the variance.

In recent years, there has been an increased interest in statistical surveillance also in other areas than industrial production. The need is great for continuous observation of time series with the aim of detecting an important change in the underlying process as soon as possible after the change has occurred. There is an increased interest in surveillance methodology in the US following the 9/11 terrorist attack. Since the collected data involve several related variables, this calls for multivariate surveillance techniques. Spatial surveillance is multivariate since several locations are involved. There have also been efforts to use multivariate surveillance for financial decision strategies by for example Okhrin and Schmid (2007) and Golosnoy, Schmid e Okhrin (2007).

The construction of surveillance methods involves statistical theory, practical issues as to the collection of new types of data, and also computational ones such as the implementation of automated methods in large scale surveillance data bases. The data is sometimes highly dimensional and collected into huge databases. Here the focus will be on the statistical inference aspects of the multivariate surveillance problem. We will focus on some general approaches for the construction of multivariate control chart methods. These general approaches do not depend on the distributional properties of the process in focus, even though the implementation does. Reviews on multivariate surveillance methods can be found for example in Basseville and Nikiforov (1993), Lowry and Montgomery (1995), Ryan (2000), Woodall and Amiriparian (2002), Frisén (2003) and Sonesson and Frisén (2005). Woodall (2007) concentrates on profile monitoring where the relation between the variables is described as a profile. 
In Section 2 the notations and specifications will be given. In Section 3, different approaches to the construction of multivariate surveillance methods are described and exemplified. In Section 4, we discuss evaluation of multivariate surveillance methods. In Section 5, we demonstrate how the relation between the change points influences the choice of optimal method. Concluding remarks are made in Section 6.

\section{Specifications}

We denote the multivariate process under surveillance by $Y=\{Y(t), t=1,2, \ldots\}$. At each time point, $t$, a $p$-variate vector $Y(t)=$ $\left(\mathrm{Y}_{1}(t) \mathrm{Y}_{2}(t) \ldots \mathrm{Y} p(t)\right)^{\mathrm{T}}$ of variables is observed. The components of the vector may be, for example, a measure of each of $p$ different components of a produced item. When the process is in control and no change has occurred, $Y(t)$ has a certain distribution (for example with a certain mean vector $\mu_{0}$ and a certain covariance matrix $\Sigma_{\gamma}$ ). The purpose of the surveillance method is to detect a deviation to a changed state as soon as possible in order to warn and to take corrective actions. We denote the current time point by $S$. We want to determine whether a change in the distribution of $Y$ has occurred up to now. Thus we want to discriminate between the events $\{\tau \leq S\}$ and $\{\tau>S\}$, where $\tau$ denotes the time point of the change. In a multivariate setting, each component can change at different times $\tau_{1}, \ldots \tau_{\mathrm{p}}$. A natural aim in many situations is to detect the first time that the joint process is no longer in control since that motivates an action. Then, it is natural to consider $\tau_{\text {min }}=\min \left\{\tau_{1}, \ldots \tau_{p}\right\}$. In order to detect the change, we can use all available observations of the process $\mathrm{Y}_{\mathrm{S}}=\{\mathrm{Y}(t), t \leq S\}$ to form an alarm statistic denoted by $p\left(Y_{\mathrm{s}}\right)$. The surveillance method makes an alarm, at the first time point when $p\left(\mathrm{Y}_{\mathrm{s}}\right)$ exceeds an alarm limit $\mathrm{G}(S)$.

\section{Constructions of multivariate control charts}

\subsection{Reduction of dimension}

A start should be to add any relevant structure to the problem in order to focus. One way to reduce dimensionality is to consider the principal components instead of the original variables as proposed for example by Jackson (1985), Mastrangelo, Runger and Montgomery (1996) and Kourti and MacGregor (1996). In Runger (1996) an alternative transformation, using so-called $\mathrm{U}^{2}$ statistics, was introduced to allow the practitioner to choose the subspace of interest, and this is used for fault patterns in Runger et al. (2007). Projection pursuit was used by Ngai and Zhang (2001) and Chan and Zhang (2001). Rosolowski and Schmid (2003) use the Mahalanobis distance to reduce the dimensionality of the statistic. After reducing the dimensionality, any of the approaches for multivariate surveillance described below can be used.

\subsection{Scalar statistics}

The most far going reduction of the dimension is to summarise the components for each time point into one statistic. This is a common way to handle multivariate surveillance problems. Sullivan and Jones (2002) referred to this as "scalar accumulation". In spatial surveillance it is common to start by a purely spatial analysis for each time point as in Rogerson (1997). A natural reduction is to use the Hotelling $\mathrm{T}^{2}$ statistic (HOTELLING, 1947). This statistic is $T^{2}(t)=\left(Y(t)-\mu_{0}(t)\right)^{T} S_{Y(t)}^{-1}$ $\left(Y(t)-\mu_{0}(t)\right)$, where the sample covariance matrix $S_{Y(t)}$ is used to estimate $\Sigma_{Y}$. When $\Sigma_{Y}$ is regarded as known and the statistic has a $\chi^{2}$ distribution, it is referred to as the $\chi^{2}$ statistic. Scalars based on regression and other linear weighting are suggested for example by Healy (1987), Kourti and MacGregor (1996) and Lu et al. (1998). Originally, the Hotelling $\mathrm{T}^{2}$ statistic was used in a Shewhart method, and this is often referred to as the Hotelling $\mathrm{T}^{2}$ control chart. An alarm is triggered as soon as the statistic $\mathrm{T}^{2}(t)$ is large enough. The reduction to a univariate variable can be followed by univariate monitoring of any kind. Note that, there is no accumulation of information over time of the observation vectors if the Shewhart method is used. In order to achieve a more efficient method, all previous observations should be used in the alarm statistic. There are several suggestions of combinations where reduction to a scalar statistic is combined with different monitoring methods. Crosier (1988) suggested to first calculate the Hotelling $\mathrm{T}$ variable (the square root of $\mathrm{T}^{2}(t)$ ) and then use this as the variable in a univariate CUSUM method, making it a scalar accumulation method. Liu (1995) used a non-parametric scalar accumulation approach, where the observation vector for a specific time point was reduced to a rank in order to remove the dependency on the distributional properties of the observation vector. Several methods were discussed for the surveillance step, including the CUSUM method. Yeh et al. (2003) suggested a 
transformation of multivariate data at each time to a distribution percentile, and the EWMA method was suggested for the detection of changes in the mean as well as in the covariance.

\subsection{Parallel surveillance}

In this commonly used approach, a univariate surveillance method is used for each of the individual components in parallel. This approach can be referred to as combined univariate methods or parallel methods. One can combine the univariate methods into a single surveillance procedure in several ways. The most common is to signal an alarm if any of the univariate methods signals. This is a use of the union-intersection principle for multiple inference problems. Sometimes the Bonferroni method is used to control a false alarm error, see Alt (1985). General references about parallel methods include Woodall and Ncube (1985), Hawkins (1991), Pignatiello and Runger (1990), Yashchin (1994) and Timm (1996).

Parallel methods suitable for different kinds of data have been suggested. Skinner, Montgomery and Runger (2003) used a generalised linear model to model independent multivariate Poisson counts. Deviations from the model were monitored with parallel Shewhart methods. In Steiner, Cook and Farewell (1999) binary results were monitored using a parallel method of two individual CUSUM methods. However, to be able to detect also small simultaneous changes in both outcome variables, the method was complemented with a third alternative, which signals an alarm if both individual CUSUM statistics are above a lower alarm limit at the same time. The addition of the combined rule is in the same spirit as the vector accumulation methods presented below. Parallel CUSUM methods were used also by Marshall et al. (2004).

\subsection{Vector accumulation}

By this approach, the accumulated information on each component is utilised by a transformation of the vector of component-wise alarm statistics into a scalar alarm statistic. An alarm is triggered if this statistic exceeds a limit. This is referred to as "vector accumulation".

Lowry et al. (1992) proposed a multivariate extension of the univariate EWMA method, which is referred to as MEWMA. This method uses a vector of univariate EWMA statistics $\mathrm{Z}(t)=\Lambda \mathrm{Y}(t)+(\mathrm{I}-\Lambda)$ $Z(t-1)$ where $Z(0)=0$ and $\Lambda=\operatorname{diag}\left(\lambda, \lambda, \ldots, \lambda_{p}\right)$. An alarm is triggered at $t_{\mathrm{A}}=\min \left\{t ; \mathrm{Z}(t)^{\top} \Sigma_{\mathrm{Z(t)}}^{-1} \mathrm{Z}(t)^{\mathrm{p}}>L\right\}$ for the alarm limit, $L$. The MEWMA method can be seen as the Hotelling $\mathrm{T}^{2}$ control chart applied to EWMA statistics instead of the original data and is thus a vector accumulation method.

One natural way to construct a multivariate version of the CUSUM method would be to proceed as for EWMA and construct the Hotelling $\mathrm{T}^{2}$ control chart applied to univariate CUSUM statistics for the individual variables. One important feature of such a method is the lower barrier (assuming we are interested in a positive change) of each of the univariate CUSUM statistics. This kind of multivariate CUSUM was suggested by Bodnar and Schmid (2004) and Sonesson and Frisén (2005). Other approaches to construct a multivariate CUSUM have also been suggested. Crosier (1988) suggested the MCUSUM method, and Pignatiello and Runger (1990) had another suggestion. Both these methods use a statistic consisting of univariate CUSUMs for each component and are thus vector accumulation methods. However, the components are used in a different way as compared with the MEWMA construction. One important feature of these two methods is that the characteristic zero-return of the CUSUM technique is constructed in a way suitable when all the components change at the same time point. However, if all components change at the same time, a univariate reduction is optimal.

\subsection{Joint solution}

The above approaches all involved stepwise constructions of methods. For complicated problems this is often useful. However, we might also aim at jointly optimal methods. Such optimality is not guaranteed by the approaches described in the sections above, which start with a reduction in either time or space (or other multivariate setting). Sometimes a sufficient reduction will result in a separation of the spatial and the temporal components. The use of the sufficient statistic implies that no information is lost. An example of this is the result by Wessman (1998) that when all the variables change at the same time, a sufficient reduction to univariate surveillance exists.

Healy (1987) derived the CUSUM method for the case of simultaneous change in a specified way for all the variables. The results are univariate CUSUMs for a function of the variables. Since the CUSUM method is minimax optimal, the multivariate methods by Healy (1987) are simultaneously minimax optimal for the specified direction when all variables change at the same time.

A way of achieving a simultaneously optimal solution is by applying the full likelihood ratio method as in Shiryaev (1963), and Frisén and de 
Maré (1991) and derive the sufficient reduction as in Frisén, Andersson and Schiöler (2010b).

\section{Evaluations of multivariate control charts}

The timeliness in detection is of importance in surveillance, and other measures than the ones traditionally used in hypothesis testing are important. To evaluate the timeliness, different measures such as the average run length, the conditional expected delay and the probability of successful detection Frisén (1992) can be used with or without modification also in a multivariate setting. The special problem of evaluation of multivariate surveillance is the topic of the paper by Frisén, Andersson and Schiöler (2010a).

Optimality is hard to achieve and even hard to define for all multivariate problems. This is so also in the surveillance case (FRISÉN, 2003). We have a spectrum of problems where one extreme is that there are hardly any relations between the multiple surveillance components. The other extreme is that we can reduce the problem to a univariate one by considering the relation between the components. Consider, for example, the case when we measure several components of an assembled item. If we restrict our attention to a general change in the factory, changes will be expected to occur for all variables at the same time. Then, the multivariate situation is easily reduced to a univariate one Wessman (1998) and we can easily derive optimal methods. For many applications, however, the specification of one general change is too restrictive. It is important to determine which type of change to focus on. The method derived according to the specification of a general change will not be capable of detecting a change in only one of many components. On the other hand, if we focus on detecting all kinds of changes, the detection ability of the surveillance method for each specific type of change will be small.

In hypothesis testing, the false rejection is considered most important. It is important to control the error in multiple testing since the rejection of a null hypothesis is considered as a proof that the null hypothesis is false. Hochberg and Tamhane (1987) described important methods for controlling the risk of an erroneous rejection in multiple comparison procedures. The False Discover Rate, FDR, suggested by Benjamini and Hochberg (1995) is relevant in situations more like a screening than as hypothesis testing. In surveillance this is further stressed as all methods with a fair power to detect a change have a false alarm rate that tends to one Bock (2008).
The problem with adopting FDR is that it uses a probability that is not constant in surveillance. Marshall et al. (2004) solve this problem as the monitoring is carried out over a short period of time and they use only the properties of the early part of the run length distribution. FDR in surveillance has been advocated for example by Rolka et al. (2007). However, the question is whether control of FDR is necessary when surveillance is used as a screening instrument, which indicates that further examination should be made. Often, the $\mathrm{ARL}^{0}$ of the combined procedure may be informative enough since it gives information about the expected time until (an unnecessary) screening. It will sometimes be easier to judge the practical burden with a too low alarm limit by the $\mathrm{ARL}^{0}$ than by the FDR for that situation.

The detection ability depends on when the change occurs is needed. The conditional expected delay $C E D(t)=\mathrm{E}\left[t_{\mathrm{A}}-\tau \mid t_{\mathrm{A}} \geq \tau=t\right]$ is a component in many measures, which avoids the dependency on $\tau$ either by concentrating on just one value of $\tau$ (e.g. one, infinity or the worst value). Frisén (2003) advocated that the whole function of $\tau$ should be studied. This measure can be generalized by considering the delay from the first change

$$
\begin{aligned}
& \tau_{\min }=\min \left\{\tau_{1}, \ldots \tau_{p}\right\} \\
& C E D\left(\tau_{1}, \ldots \tau_{p}\right)=E\left(t_{A}-\tau_{\text {min }} \mid t_{A} \geq \tau_{\min }\right)
\end{aligned}
$$

The Probability of Successful Detection suggested by Frisén (1992) measures the probability of detection with a delay time shorter than $d$. In the multivariate case it can be defined as

$$
P S D\left(d, \tau_{1}, \ldots \tau_{p}\right)=P\left(t_{A}-\tau_{\min } \leq d \mid t_{A} \geq \tau_{\min }\right)
$$

This measure depends on both the times of the changes and the length of the interval in which the detection is defined as successful. Also, when there is no absolute limit to the detection time it is often useful to describe the ability to detect the change within a certain time. In such cases, it may be useful to calculate the PSD for different time limits $d$. This has been done for example by Marshall et al. (2004) in connection with use of the FDR. The ability to make a very quick detection (small d) is important in surveillance of sudden major changes, while the long-term detection ability (large d) is more important in ongoing surveillance where smaller changes are expected.

Since the above measures of delay are complex, it is tempting to use the simple ARL measure. The ARL' is the most commonly used measure of the detection ability also in the multivariate case. 
It is usually assumed that all variables change immediately. However, the results by Wessman (1998) are that univariate surveillance is always the best method in this setting. Thus, for genuinely multivariate situations with different change points, $\mathrm{ARL}^{1}$ is not recommended other as a rough indicator.

\section{The effect of the relation between the change points}

In order to illustrate principles and measures we will compare one method using reduction to one scalar for each time (Method M1) with one using parallel control charts (Method M2). Method M1 gives an alarm if the the sum of the variables exceeds a limit. That is $t_{\mathrm{A}}=\min \left\{t ; \mathrm{X}(t)+\mathrm{Y}(t)>\mathrm{G}_{\mathrm{M} 1}\right\}$. Method M2 gives an alarm if the method gives an alarm for any of the variables. "That is $t_{\mathrm{A}}=\min \left\{\mathrm{t} ; \mathrm{X}(t)>\mathrm{G}_{\mathrm{M} 2} \cup \mathrm{Y}(t)>\mathrm{G}_{\mathrm{M} 2}\right\}$. The limits were determined for the Shewhart method to $\mathrm{G}_{\mathrm{M} 1}=3,29$ and $\mathrm{G}_{\mathrm{M} 2}=2,57$ so that $\mathrm{ARL}^{0}=100$ for both $\mathrm{M} 1$ and $\mathrm{M} 2$.

In the first situation, both variables shift at the same time. That is $\tau_{x}=\tau_{\gamma}$. The method M1 has the conditional expected delay CED $=1,39$ while $\mathrm{M} 2$ has $\mathrm{CED}=2,09$. The probability to detect the out-ofcontrol state immediately $\operatorname{PSD}(0, t)$ is for the $\mathrm{M} 1$ method PSD = 0,42 and for M2 we have PSD = 0,32. Thus, we see that if both methods shift at the same time it is best to use the univariate sum as alarm statistic. This is also in accordance with theory.

In the second situation one variable does not shift, while the other one does. However, we do not know beforehand which one it might be. For the case when $X$ in fact did not change $\left(\tau_{x}=\infty\right)$ but $\mathrm{Y}$ did we have $\tau_{\min }=\tau_{\gamma}$. The method $\mathrm{M} 1$ has the conditional expected delay CED $=4,53$ and $\mathrm{M} 2$ has $\mathrm{CED}=2,49$. For the $\mathrm{M} 1$ method $\mathrm{PSD}=0,18$ and for $\mathrm{M} 2 \mathrm{PSD}=0,29$. Thus, we see that if only one out of several processes changes the properties of M2 are much better.

In the third situation we know that only the distribution of $Y$ can change. We can thus focus on $\mathrm{Y}$ only. If this had been the case the univariate Shewhart method would have had CED $=1,69$. The probability to detect the out-of-control state immediately would have been $\operatorname{PSD}(0, t)=0,37$. Thus, the knowledge would have improved the detection ability (for the same $\mathrm{ARL}^{\circ}$ ) considerably.

\section{Conclusions}

Methods can be characterised as scalar accumulating, parallel, vector accumulating or simultaneous. However, there is no sharp limit between some of these categories. Many methods first reduce the dimension for example by principal components, and then one of the approaches for multivariate surveillance is used. Fuchs and Benjamini (1994) suggest Multivariate Profile Charts that demonstrate both the overall multivariate surveillance and individual surveillance in the same chart and thus combine two of the approaches.

The more clearly the aim is stated, the better the possibilities of the surveillance to meet this aim. Hauck, Runger and Montgomery (1999) describe how a change may influence variables and the relation between them. One way to focus the detection ability is by specifying a loss function with respect to the relative importance of changes in different directions. Mohebbi and Havre (1989) use weights from a linear loss function instead of the covariance for the reduction to a univariate statistic. Tsui and Woodall (1993) use a non-linear loss function and a vector accumulation method named MLEWMA. For some methods, the detection ability depends only on one non-centrality parameter which measures the magnitude of the multi-dimensional change. Such methods are known as "directionally invariant". However, this is not necessarily a good property in all situations, since there often is an interest in detecting a certain type of change. Fricker (2007) stresses the importance of directionally sensitive methods for syndromic surveillance. Preferably, the specification should be governed by the application.

The question of which multivariate surveillance method is the best has no simple answer. Different methods are suitable for different problems as was demonstrated by the examples in Section 5 . Some causes may lead to a simultaneous increase in several variables, and then one should use a reduction to a univariate surveillance method, as shown by Wessman (1998) and demonstrated here by the examples. If the changes occur independently, one does not expect simultaneous changes and may instead prefer to use parallel methods. All knowledge on which component to concentrate on is useful.

One advantage with parallel methods is that the interpretation of alarms will be clear. The identification of why an alarm was raised is important. The Hotelling $\mathrm{T}^{2}$ control chart is not able to distinguish between a change in the mean vector and a change in the covariance structure. Mason, Tracy and Young (1995) provided a general approach by a decomposition of the $\mathrm{T}^{2}$ statistic into independent components. Other suggestions include for example principal component analysis, see Pignatiello and Runger (1990), Kourti and MacGregor (1996) and Maravelakis et al. (2002). 
The importance of knowledge about where to concentrate the effort after an alarm indicating a bioterrorist attack is discussed by Mostashari and Hartman (2003).

The evaluations of multivariate control charts are considerately more complex than for univariate ones. However, the effort to specify the problem is rewarding. Simple measures might be misleading.

\section{References}

ALT, F. B. Multivariate quality control. In: JOHNSON, N. L.; KOTZ, S. (Ed.). Encyclopedia of Statistical Science. New York: Wiley, 1985.

BASSEVILLE, M.; NIKIFOROV, 1. Detection of abrupt changes - Theory and application. Englewood Cliffs: Prentice Hall, 1993.

BENJAMINI, Y.; HOCHBERG, Y. Controlling the false discovery rate: a practical and powerful approach to multiple testing. Journal of the Royal Statistical Society B, v. 57, p. 289-300, 1995.

BOCK, D. Aspects on the control of false alarms in statistical surveillance and the impact on the return of financial decision systems. Journal of Applied Statistics, v. 35, p. 213-227, 2008.

BODNAR, 0.; SCHMID, W. Year. CUSUM control schemes for multivariate time series. In: FRONTIERS in statistical quality control. Intelligent statistical quality control. Warsaw, 2004.

CHAN, L. K.; ZHANG, J. Cumulative sum control charts for the covariance matrix. Statistica Sinica, v. 11, p. 767-790, 2001.

CROSIER, R. B. Multivariate generalizations of cumulative sum quality-control schemes. Technometrics, v. 30, p. 291-303, 1988.

FRICKER, R. D. Directionally sensitive multivariate statistical process control procedures with application to syndromic surveillance. Advances in Disease Surveillance, v. 3, p. 1-17, 2007.

FRISÉN, M. Evaluations of methods for statistical surveillance. Statistics in Medicine, v. 11, p. 1489-1502, 1992.

FRISÉN, M. Statistical surveillance. Optimality and methods. International Statistical Review, v. 71, p. 403-434, 2003.

FRISÉN, M.; ANDERSSON, E.; SCHIÖLER, L. Evaluation of multivariate surveillance. Journal of Applied Statistics, 2010a.

FRISÉN, M.; ANDERSSON, E.; SCHIÖLER, L. Sufficient reduction in multivariate surveillance. Communications in Statistics - Theory and Methods, 2010b.

FRISÉN, M.; DE MARÉ, J. Optimal surveillance. Biometrika, v. 78, p. 271-80, 1991.

FUCHS, C.; BENJAMINI, Y. Multivariate profile charts for statistical process control. Technometrics, v. 36, p. 182-195, 1994

GOLOSNOY, V.; SCHMID, W.; OKHRIN, 1. Sequential monitoring of optimal portfolioweights. In: FRISÉN, M. (Ed.). Financial surveillance. Chichester: Wiley, 2007.

HAUCK, D. J.; RUNGER, G. C.; MONTGOMERY, D. C. Multivariate statistical process monitoring and diagnosis with grouped regression-adjusted variables. Communications in Statistics. Simulation and Computation, v. 28, p. 309-328, 1999.

HAWKINS, D. M. Multivariate quality control based on regression-adjusted variables. Technometrics, v. 33, p. 61-75, 1991.

HEALY, J. D. A note on multivariate CUSUM procedures. Technometrics, v. 29, p. 409-412, 1987.

HOCHBERG, Y.; TAMHANE, A. C. Multiple comparison procedures. New York: Wiley, 1987.

HOTELLING, H. Multivariate quality control. In: EISENHART, C.; HASTAY, M. W.; WALLIS, W. A. (Ed.). Techniques of statistical analysis. New York: McGraw-Hill, 1947.

JACKSON, J. E. Multivariate quality control. Communications in statistics. Theory and methods, v. 14, p. 2657-2688, 1985.

KNOTH, S.; SCHMID, W. Monitoring the mean and the variance of a stationary process. Statistica Neerlandica, v. 56, p. 77-100, 2002.

KOURTI, T.; MACGREGOR, J. F. Multivariate SPC methods for process and product monitoring. Journal of Quality Technology, v. 28, p. 409-428, 1996.

LIU, R. Y. Control charts for multivariate processes. Journal of the American Statistical Association, v. 90, p. 1380-1387, 1995.

LOWRY, C. A. et al. A multivariate exponentially weighted moving average control chart. Technometrics, v. 34, p. 46-53, 1992.

LOWRY, C. A.; MONTGOMERY, D. C. A review of multivariate control charts. IIE Transactions, v. 27, p. 800-810, 1995.

LU, X. S. et al. Control chart for multivariate attribute processes. International Journal of Production Research, v. 36 , p. $3477-3489,1998$.

MARAVELAKIS, P. E. et al. Identifying the out of control variable in a multivariate control chart. Communications in Statistics. Theory and Methods, v. 31, p. 2391-2408, 2002.

MARSHALL, C. et al. Statistical issues in the prospective monitoring of health outcomes across multiple units. Journal of the Royal Statistical Society A, v. 167, p. 541-559, 2004.

MASON, R. L.; TRACY, N. D.; YOUNG, J. C. Decomposition of $\mathrm{T}^{2}$ for multivariate control chart interpretation. Journal of Quality Technology, v. 27, p. 99-108, 1995.

MASTRANGELO, C. M.; RUNGER, G. C.; MONTGOMERY, D. C. Statistical process monitoring with principal components. Quality and Reliability Engineering International, v. 12, p. 203-210, 1996

MOHEBBI, C.; HAVRE, L. Multivariate control charts: A loss function approach. Sequential Analysis, v. 8, p. 253-268, 1989.

MOSTASHARI, F.; HARTMAN, J. Syndromic surveillance: a local perspective. Journal of Urban Health, v. 80, p. 11-17, 2003.

NGAl, H. M.; ZHANG, J. Multivariate cumulative sum control charts based on projection pursuit. Statistica Sinica, v. 11, p. 747-766, 2001.

OKHRIN, Y.; SCHMID, W. Surveillance of univariate and multivariate nonlinear time series. In: FRISÉN, M. (Ed.). Financial surveillance. Chichester: Wiley, 2007. 
PIGNATIEllo, J. J.; RUNGER, G. C. Comparisons of multivariate CUSUM charts. Journal of Quality Technology, v. 22, p. 173-186, 1990.

ROGERSON, P. A. Surveillance systems for monitoring the development of spatial patterns. Statistics in Medicine, v. 16, p. 2081-2093, 1997.

ROLKA, H. et al. Issues in applied statistics for public health bioterrorism surveillance using multiple data streams: research needs. Statistics in Medicine, v. 26, p. 1834-1856, 2007.

ROSOLOWSKI, M.; SCHMID, W. EWMA charts for monitoring the mean and the autocovariances of stationary Gaussian processes. Sequential Analysis, v. 22, p. 257-285, 2003.

RUNGER, G. C. et al. Optimal monitoring of multivariate data for fault detection. Journal of Quality Technology, v. 39, p. 159-172, 2007.

RUNGER, G. C. Projections and the $\mathrm{U}^{2}$ chart for multivariate statistical process control. Journal of Quality Technology, v. 28, p. 313-319, 1996.

RYAN, T. P. Statistical methods for quality improvement. New York: Wiley, 2000.

SAHNI, N. S.; AASTVEIT, A. H.; NAES, T. In-Line process and product control using spectroscopy and multivariate calibration. Journal of Quality Technology, v. 37, p. 1-20. 2005.

SHEWHART, W. A. Economic control of quality of manufactured product. London: MacMillan and Co., 1931.

SHIRYAEV, A. N. On optimum methods in quickest detection problems. Theory of Probability and its Applications, v. 8, p. 22-46, 1963.

SKINNER, K. R.; MONTGOMERY, D. C.; RUNGER, G. C. Process monitoring for multiple count data using generalized linear model-based control charts. International Journal of Production Research, v. 41, p. 1167-1180, 2003.

SONESSON, C.; FRISÉN, M. Multivariate surveillance. In: LAWSON, A.; KLEINMAN, K. (Ed.). Spatial surveillance for public health. New York: Wiley, 2005.
STEINER, S. H.; COOK, R. J.; FAREWELL, V. T. Monitoring paired binary surgical outcomes using cumulative sum charts. Statistics in Medicine, v. 18, p. 69-86, 1999.

SULLIVAN, J. H.; JONES, L. A. A self-starting control chart for multivariate individual observations. Technometrics, v. 44, p. 24-33, 2002.

TIMM, N. H. Multivariate quality control using finite intersection tests. Journal of Quality Technology, v. 28, p. 233-243, 1996.

TSUI, K. L.; WOODALL, W. H. Multivariate control charts based on loss functions. Sequential Analysis, v. 12, p. 79-92, 1993.

TSUNG, F.; LI, Y.; JIN, M. Statistical process control for multistage manufacturing and service operations: a review and some extensions International Journal of Services Operations and Informatics, v. 3, p. 191-204, 2008.

WÄRMEFJORD, K. Multivariate quality control and diagnosis of sources of variation in assembled products. Thesis (Licentiat)-Göteborg University, 2004.

WESSMAN, P. Some Principles for surveillance adopted for multivariate processes with a common change point. Communications in Statistics. Theory and Methods, v. 27, p. 1143-1161, 1998.

WOODALL, W. H. Current research on profile monitoring. Produção, v. 17, p. 420-425, 2007.

WOODALL, W. H.; AMIRIPARIAN, S. On the economic design of multivariate control charts. Communications in Statistics - Theory and Methods, v. 31, p. 1665-1673, 2002.

WOODALL, W. H.; NCUBE, M. M. Multivariate cusum quality control procedures. Technometrics, v. 27, p. 285-292, 1985.

YASHCHIN, E. Monitoring variance components. Technometrics, v. 36, p. 379-393, 1994.

YEH, A. B. et al. A multivariate exponentially weighted moving average control chart for monitoring process variability. Journal of Applied Statistics, v. 30, p. 507-536, 2003.

\section{Sobre gráficos de controle multivariados}

\section{Resumo}

A produção industrial requer o uso de gráficos de controle para permitir o monitoramento de vários componentes. Recentemente tem havido um aumento de interesse também em outras áreas como a detecção do bioterrorismo, vigilância espacial e estratégias de operação na área financeira. Na literatura, vários tipos de gráficos multivariados têm sido propostos contrapondo-se aos gráficos univariados de Shewhart, EWMA e CUSUM. Uma revisão geral sobre os gráficos de controle multivariados é apresentada. Sugestões são dadas em especial aos desafios em avaliar métodos multivariados em vigilância.

\section{Palavras-chave}

Vigilância. Monitoramento. Controle de qualidade. Avaliação multivariada. Suficiência. 